and it is suggested that possibly the services of this committee might be of some assistance at the present time."

To this letter the following reply was received :-

"A August 17, 1917.

SIR,-I am commanded by the Army Council to acknowledge the receipt of your letter of the 4th inst., and in reply to inform you that the visual requirements of the various branches of the Army are dependent in the first place upon the conditions appertaining to the respective arms of the service, and are determined by the military authorities. The translation of these requirements into optical language is then effected by the military medical authorities. If there is any change proposed in the standard, the Council will be glad :o avail themselves of the advice of the Ophthalmological Society of the United Kingdom, and I am to express the thanks of the Army Council to your Society for their kind offer of assistance.

$$
\begin{aligned}
& \text { I am, Sir, } \\
& \text { Your obedient Servant, }
\end{aligned}
$$

B. B. Cubitt."

With this reply before them, the committee are obliged to report that they are not able to obtain the necessary evidence on the many important and interesting matters connected with the visual requirements of the Army which require investigation - an investigation which, in its opinion, would tend not only to increase the efficiency of the Army, but also be likely to save much needless expenditure of time and material.

$$
\begin{aligned}
& \text { (Signed), E. TReacher Collins (Chairman). } \\
& \text { RICHARD R. CRUISE. } \\
& \text { W. T. Lister (Temp. Col., A.M.S.) } \\
& \text { GEORGE MACKAY. } \\
& \text { W. H. MCMUllen (Hon. Sec.) } \\
& \text { ARTHUR W. ORMOND. } \\
& \text { J. Herbert Parsons. } \\
& \text { W. T. HOLMES SPICER. }
\end{aligned}
$$

Addendum by Major A. W. Ormond :-

"It is only right to point out that the letter represents the only communication made to the War Office, the Report having been drawn up subsequently."

\title{
ANNOTATIONS
}

\section{The Visual Requirements of Soldiers}

Up to the present time our military standards of vision, which govern the acceptance or rejection of recruits for the army, have been based upon theory and assumption. ' We have little or no 
definite information, derived from actual experimental work, in connection with the multifarious functions that soldiers may be called upon to perform, as to what degree of vision is compatible with efficiency in regard to any particular form of military duty. The standards for the various arms have been adopted on the recommendation of military (not medical) officers who reached their conclusions independent of any sort of experimental evidence.

In earlier days, when fighting took place at close range, when Brown Bess carried 50 yards and commanders wished for bullets as big as oranges, general physical fitness was looked to and the special senses were but little regarded. Thus we find that as late as 1837, ability to detect a person at ten paces was considered adequate in one continental army. With the advent of "weapons of precision" it was at first, and, indeed, until recently, supposed that battles would be decided at several hundred yards distance, and good vision began to be regarded practically as a necessity. Alas for theory! Our experts might have borne in mind the story of King Charles and the goldfish. Apart from other essentials, we now know that artillery, who may never see their target, are of prime importance, while the final decision is brought about by bombs, bayonets, and even fists. It is recognized that battles are fought and won by organized hosts of specialists selected and classified according to their individual fitness for their particular functions. An army has its eyes, its ears, its legs, and its stomach, as well as its weapons, and behind all these its brains. Not one, then, but many standards of vision are required, and a standard compatible with efficiency in one branch of the service, would be absurd if applied to another.

When all that is aimed at is a small standing army of picked men, the question of vision does not arise. It is easy to adopt a high standard and to reject without further enquiry all recruits who fail to reach it. When, however, the number of recruits required in proportion to the population begins to increase, the reasons for rejection require examination. And, lastly, when the manhood of a nation is under arms, and it becomes necessary to see that the best use is made of each individual unit, theoretic standards can no longer be accepted, and the closest scrutiny of the subject becomes essential.

These conditions have been gradually growing up in the armed camp of the continent of Europe for the last fifty years, and, in consequence, endeavours have been made by means of statistical and experimental work to obtain some information as to military visual efficiency. The study of military ophthalmology has been begun and a considerable literature already exists. With us, on the other hand, the causes of such a development have never existed, and, as a result, we have no military ophthalmology, no 
real information on the visual requirements of soldiers, only a rather nebulous empirical standard, the outcome of our necessities.

It has been said that any man who is able to earn a living in civil life is able to be of some use in the army. While such a generalization must have many exceptions, even when the army is the nation in arms, we shall not be wide of the mark if we state as a guiding principle that any man, otherwise physically fit, whose vision is such that he can earn a living in civil life, is capable of efficient service in some military capacity. Although this principle is already largely recognized, it has not yet found adequate expression in the formulation of a rational and comprehensive military visual standard.

Having regard to the necessities of a nation under arms, to the absence of evidence in connection with the vision necessary for soldiers, to the heterogeneous nature of military duties, and to what we know of the visual requirements of workmen, who often earn full wages with what seems to be astonishingly inadequate vision, such suggestions as can now be put forward may be regarded as propositions to be accepted until they are shown to be impracticable by experience or experimental investigation. It is necessary also to remember that the use of Snellen's test card aflords an extremely unsatisfactory indication as to visual capacity; and, lastly, that the intelligence of the individual is a factor of the greatest importance. An intelligent man with bad vision will be of more use than a stupid man with much better sight.

The vision required for the different branches of the service can only be ascertained by experience and experiment, by conversation with men who have been at the front in various capacities, and by observations made on troops working under war conditions or on manoeuvres. Though theoretic standards may serve their purpose when a high percentage of rejections is of no consequence, they are in present conditions unnecessarily high. This is due to the estimation of visual efficiency in terms of visual acuity as measured by Snellen's test; or, one might say, to neglect of the fact that visual efficiency depends more on the intelligent interpretation of retinal images, even if indistinct, than on the mere existence of clear images. Hence it has often been supposed that savages have specially acute sight. In some ways this is true, but it is cerebral rather than ocular vision.

When so little is really known about the minimum vision compatible with efficiency in any form of employment, military or otherwise, it would be futile to attempt any minute classification. With regard to infantry, it should be remembered that good vision is only one of the factors involved in good shooting, and, in itself, is not a dependable guide. All infantry are not "snipers," yet an examination by Snellen's types of the visual acuity of "crack shots". 
would surprise many theorists. The soldier who is to shoot should have 6/12 (corrected) in one eye, either right or left. Men who are blind in one eye should not be refused. Left eye shots, and those who shoot with both eyes open, have been found to make good marksmen, and are accepted in the French Army, and probably others.

Aviators may require a somewhat higher standard than the infantry; but here again only experience and investigation can provide trustworthy information. The present standard is probably needlessly high, at least as regards the second eye. The absence of binocular vision is usually only important when the loss has been recent. Even the necessity for good colour vision, which seems so obvious, has been disputed. Intelligence and the power of correctly interpreting what is seen are factors which will often more than compensate for apparently inadequate vision. Many a good man may be lost to the R.F.C. by a verdict based on Snellen's types.

When the vision of one eye is sufficient the amount required in the other is an important question. A short time ago two private soldiers were seen. One was a strong young colonial who had suffered from intra-ocular haemorrhages apparently the effects of a shell burst. R.V. 6/18. L.V. $<6 / 60$. He stated that he had been discharged owing to his vision. The other was an older man, of relatively inferior physique, with high myopia in his right eyę and nebulae. The left eye presented an extensive and dense leucoma with a breaking-down surface. R.V. with - 13D. sph. combined with $-4 \cdot 0$ cyl. $=6 / 18$ part. He stated that he had been rejected four times before being accepted. The visual capacity of the former was undoubtedly the greater. The abilities of men with only uniocular vision in civil life should be taken into consideration, and a practical view should be taken of this question. Men with squint, unilateral amblyopia, aphakia, cataract, traumatic optic atrophy, and a large number of other non-progressive morbid conditions in one eye, find themselves in no way impeded in civil life, and need be no less efficient as private soldiers than as admirals and generals.

Any consideration of the position of our present knowledge of the visual requirements of soldiers brings at least one point into prominence, namely, the urgent necessity for the proper recognition of ophthalmology by the military authorities, and the establishment of the study of military ophthalmology upon a scientific basis.

Military medical officers should be thoroughly grounded in eye work, especially in its relation to the estimation of visual capacity, and a sufficient knowledge of what is necessary cannot be acquired even by the ablest medical officer in a short course of instruction.

Some better means of estimating visual capacity than Snellen's types are required. Here it may be mentioned that the practice of regarding " $6 / 18$ " as " $1 / 3$ of normal vision," and so on, 
cannot be too strongly condemned. The question of testing recruits out of doors at a distance greater than 20 feet; also requires consideration.

These and a host of other problems await solution. Even if universal peace arrives the work will not be wasted, for the results will be of great value in connection with industrial questions.

\section{The War and the American Ophthalmological Society}

At the last meeting (May, 1917) of the American Ophthalmological Society the Council presented, and the members adopted, a series of resolutions dealing with the relationship to be held by ophthalmologists to the war.

It was first pointed out that in the present crisis the Government would need the services of every available medical man, and that the number of ophthalmologists in the regular medical department was too small to meet the requirements, and the Council insisted that the present classification of ophthalmologists as surgeons had a tendency to prevent volunteering, because "it is apt to assign to men of special training work for which they are unfitted, and to remove them from work of great importance which they can do." The Council accordingly placed on record its opinion, " that ophthalmologists be classed as a separate division of the Medical Department." It was recommended that a survey be made of the ophthalmologists of the United States for duties in various branches, as the examination of vision in recruits, the detection of malingerers, and the inspection of hospitals; and it was advised that the proper persons to conduct this survey were the members of the sub-committee on ophthalmology of the Council of National Defence. Further recommendations included the following:- "That the Society respectfully petitions the Surgeon-General of the United States Army to appoint this sub-committee on ophthalmology to make a review of the ophthalmic profession of the country, and submit to the Department lists of men best qualified to fulfil the various duties falling upon ophthalmologists," and "that the Surgeon-General be further petitioned to follow the recommendations of this Board as closely as is consistent with the good of the service, requesting the men selected by the Board . . . . to volunteer for such service as the Board may designate."

At the same meeting the Secretary was requested to send the following communication to each member of the Society now on war duty atroad :-

"The Secretary is requested to extend to you the cordial greetings of the American Ophthalmological Society, and convey to 